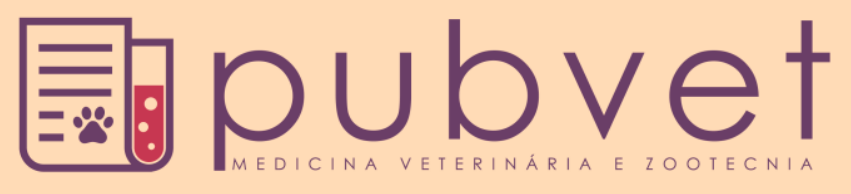

https://doi.org/10.31533/pubvet.v12n9a179.1-6

\title{
Efeito de imunoestimulante no tratamento de coccidiose de bezerros
}

\section{Cássio Henrique Martins Morais ${ }^{1} \bullet$, Nadia Cristine Weinert $^{2} \odot$, Mariana Marcantonio Coneglian $^{3 \oplus}$, Heloisa Godoi Bertagnon ${ }^{*} \odot$}

${ }^{I}$ Discente da Universidade Estadual do Centro-Oeste, Departamento de Medicina Veterinária, Guarapuava -PR, Brasil. ${ }^{2}$ Doutoranda da Universidade Estadual de Londrina, Departamento de Patologia animal, Londrina -PR, Brasil.

${ }^{3}$ Docente da Universidade Estadual do Centro-Oeste, Departamento de Medicina Veterinária, Guarapuava -PR, Brasil.

${ }^{4}$ Docente, Universidade Estadual do Centro-Oeste, Departamento de Medicina Veterinária, Guarapuava-PR, Brasil. hbertagnon@hotmail.com *Autor para correspondência.

RESUMO. A coccidiose é uma das principais enfermidades do trato gastrointestinal dos ruminantes, manifestada por alterações sutis como redução de ganho de peso até quadros de diarreia aquosa à sanguinolenta. Na sua forma clínica, o comprometimento da mucosa intestinal prejudica a absorção de nutrientes provindos da dieta, culminando em atrasos na recuperação clínica dos animais. Desta maneira o presente trabalho pretendeu avaliar a eficácia de dois tratamentos na recuperação clínica da coccidiose em bezerros leiteiros em fase de crescimento por meio de avaliação de hematócrito, proteína e fibrinogênio plasmático, leucograma, contagem de ovos por gramas de fezes, inspeção visual do pelame e incidência de diarreia. Para tanto, sete bezerros da raça Jersey entre 2 a 6 meses de idade, com coccidiose foram divididos em dois grupos conforme o tratamento. O grupo antibiótico mais catofós (C), com quatro bezerros, foi tratado com sulfametoxazol + trimetoprim e com o imunoestimulante butafosfan+ vitamina B12 (Catofós $®$ ), ambos em dose única, e o grupo antibiótico (A), com três bezerros, foi tratado apenas com sulfametoxazol + trimetoprim em dose única. Observou-se que ambos os tratamentos empregados foram eficazes no combate da enfermidade, reduzindo a sintomatologia da doença, melhorando o pelame dos animais e negativando o exame coproparasitológico. Embora os parâmetros de leucograma, fibrinogênio e proteína plasmática não tenham alterado com os tratamentos, o grupo tratado com antibiótico mais catofós teve um aumento significativo no hematócrito, permitindo comprovar a eficiência de ambos os fármacos.

Palavras-chave: butafosfan, diarreia, hematócrito, oocistos

\section{Imunostimulant effects on coccidioses treatment of calves}

ABSTRACT. Coccidiosis is one of the main diseases of the gastrointestinal tract of ruminants, manifested by subtle changes such as reduction of weight gain, watery diarrhea until bloody diarrhea. In its clinical form, the intestinal mucosa compromises the absorption of nutrients from the diet, culminating in delays in the clinical recovery of the animals. The present work aimed to evaluate the efficacy of two treatments in the clinical recovery of coccidiosis in growing dairy calves by evaluating hematocrit, protein and fibrinogen plasmatic, leucogram, egg count per gram of feces, visual inspection of the pelage and incidence of diarrhea. Seven Jersey calves between 2 and 6 months of age with coccidiosis were divided into two groups according to the treatment. The antibiotic and catofos group (C), with four calves, was treated with sulfamethoxazole + trimethoprim and the immunostimulant butafosfan + vitamin B12 (Catofós®), both in a single dose, and the antibiotic group (A) with three calves was treated with only sulfamethoxazole + trimethoprim in a single dose. It was observed that both treatments were effective in combating the disease, reducing the symptomatology of the disease, improving the pelage 
of the animals and negatively coproparasitological examination. Although the parameters leukogram, fibrinogen and protein plasmatic did not change with the treatments, the antibiotic and catofos group had a significant increase in the hematocrit, allowing to prove the efficiency of both drugs.

Keywords: butafosfan, diarrhea, hematocrit, oocysts

\section{Efecto de inmunoestimulante en el tratamiento de coccidiosis de terneros}

RESUMEN. La coccidiosis es una de las principales enfermedades del tracto gastrointestinal de los rumiantes, manifestada por alteraciones sutiles como reducción de ganancia de peso hasta cuadros de diarrea acuosa a sanguinolenta. em su forma clínica, El comprometimiento de la mucosa intestinal perjudica la absorción de nutrientes provenientes de la dieta, culminando em retrasos em la recuperación clínica de los animales. De esta manera el presente trabajo evaluó la eficacia de dos tratamientos en la recuperación clínica de la coccidiosis em terneros lecheros en fase de crecimiento por medio de evaluación de hematocrito, proteína y fibrinógeno plasmático, leucograma, recuento de huevos por gramos de heces, inspección visual del pelaje y la incidencia de diarrea. Para ello, siete terneros de la raza jersey entre 2 a 6 meses de edad, con coccidiosis se dividieron en dos grupos según El tratamiento. El grupo antibiótico más Catafos ${ }^{\circledR}(C)$, con cuatro terneros, fue tratado con sulfametoxazol + trimetoprim y con el inmunoestimulante butafosfan+ vitamina B12 (Catofós $\left.{ }^{\circledR}\right)$, ambos en una sola dosis, y el grupo antibiótico (A), con tres terneros, fue tratado solo con sulfametoxazol + trimetoprimen una sola dosis. Se observó que ambos tratamientos empleados fueron eficaces en el combate de la enfermedad, reduciendo la sintomatología de la enfermedad, mejorando el pelaje de los animales y dando negativo al examen coproparasitológico. Aunque los parámetros de leucograma, fibrinógeno y proteína plasmática no cambiaron con los tratamientos, el grupo tratado antibiótico más Catofós ${ }^{\circledR}$ tuvo un aumento significativo em el hematocrito, permitiendo comprobar la eficiencia de ambos fármacos.

Palabras clave: butafosfan, diarrea, hematocrito, ovocitos

\section{Introdução}

A coccidiose é uma das principais parasitoses intestinais de animais de produção, pois ocasiona prejuízos consideráveis decorrentes de retardo de ganho de peso até mortalidade de animais, sendo mais grave em bezerros leiteiros na fase do desmame (Lima, 2004; Carlson et al., 2011).

A apresentação mais comum da doença é a subclínica, caracterizada por redução do desempenho produtivo. Já a forma clínica observa-se presença de diarreia intensa, que pode durar dias, podendo resultar no óbito do animal (Radostits et al, 2007).

A sintomatologia dos animais dependerá da intensidade da lesão causada pelos coccídeos no intestino. Estes parasitas causam a destruição de células das vilosidades intestinais que são substituídas por células de áreas adjacentes. Tal fato reduz o tamanho das vilosidades e somado a baixa diferenciação das células absorventes, resultam em menor capacidade digestiva e absortiva resultando em diarreia e diminuição da capacidade produtiva do animal (Moon, 1980; Nielsen, 1982).

O diagnóstico da coccidiose baseia-se na anamnese, sinais clínicos do animal, exame coproparasitológico e até lesões características no intestino,como edema de mucosa identificadas no exame necroscópico (Oliveira et al., 2007).

O tratamento é realizado por meio de drogas específicas, como antimicrobianos, amprólio, decoquinato, antibióticos ionofóros e toltrazuril, cuja eficiência é maior nas fases iniciais da doença, pois ainda não ocorreu alterações intestinais permanentes. Como a fase inicial da doença pode ser silenciosa, recomenda-se tratar todos os animais mantidos no ambiente contaminado e isolar os animais doentes para diminuir a contaminação do meio ambiente (Lima, 2004).

Este trabalho objetivou verificar a eficácia de dois tratamentos contra coccidiose em bezerros com diarreia e presença de oocisto nas fezes, sendo realizado ambos com sulfametoxazol + trimetoprim acrescida ou não do 
imunoestimulante butafosfan e cianocobalamina, sendo os parâmetros clínicos e laboratoriais avaliados.

\section{Material e métodos}

No dia 5 de julho de 2017 foram atendidos no setor de Grandes Animais da Clínica Escola de Veterinária (CEVET) da Universidade Estadual do Centro Oeste (UNICENTRO) sete bezerros, da raça Jersey, com idade entre dois a seis meses de vida e peso médio de $110 \mathrm{~kg}$. Os bezerros chegaram a clínica com quadro de diarreia. Constatou-se que os animais do rebanho tinham o histórico de diarreia no período pós desmame, desidratação e em raras ocasiões óbito, havendo na necropsia, espessamento de mucosa de colón menor compatível com lesão de coccidiose. Os bezerros entre dois a sete meses permaneciam sempre no mesmo pasto, não havendo rotação de pastagem.

No exame físico dos animais analisados no presente estudo, notou-se diarreia profusa, perda progressiva de peso, desidratação de 5\%, caquexia, pêlos opacos e arrepiado. Na avaliação das fezes, notou-se a presença de sangue oculto na prova utilizando peróxido de hidrogênio (água oxigenada).

Os sinais clínicos encontrados associados ao histórico da propriedade eram sugestivos de um quadro de coccidiose. Amostras de fezes de todos os animais foram enviadas para o Laboratório de Doenças Infecciosas e Parasitárias, a fim de se confirmar esta suspeita. Com este exame foi possível quantificar os oocistos e assim fechar o diagnóstico de coccidiose.

A partir dos resultados coproparasitológicos, dividiu-se os sete animais com coccidiose em um dos tratamentos, a saber: o grupo antibiótico, composto por 3 animais, que recebeu o tratamento com sulfametoxazol + trimetoprim (Mastissulfa ${ }^{\circledR}$, JA saúde animal, São Paulo) (A), em aplicação única, na dose de $32 \mathrm{mg} / \mathrm{Kg}$, e o grupo antibiótico +Catofós (C) composto por 4 animais, que recebeu, a antibioticoterapia acima mencionada associada a butafosfan, na dose de $1 \mathrm{~g}$ por animal associado a cianocobalamina, na dose de $0,5 \mathrm{mg}$ por animal (Catofós®, JA saúde animal, São Paulo).

As avaliações dos tratamentos foram realizadas por meio de exame coproparasitológico, realizada pela técnica de quantificação de oocistos por grama de fezes (OPG), em amostras de fezes colhidas diretamente da ampola retal. Nas amostras de sangue, colhidas da jugular externa em frascos com EDTA, realizou-se o hematócrito, leucograma, proteína e fibrinogênio plasmático antes e sete dias após o tratamento. O hematócrito foi realizado em microcentrífuga, o leucograma foi realizado por contagem manual em câmara de Neubauer e a contagem diferencial foi avaliada em microscopia óptica nos esfregaços sanguíneos. A proteína e o fibrinogênio foram mensurados por refratômetria.

Os dados foram tabulados e submetidos a análise estatística pelo programa Graph Pad Instat ${ }^{\circledR}$, sendo considerados significativos quando valor de $\mathrm{p} \leq 0,05$.

\section{Resultados e discussão}

Todos os animais diagnosticados com coccidiose apresentavam idade entre dois e seis meses, casuística esperada no gado leiteiro, onde a prevalência da coccidiose em bezerros de até um ano é de até 46\% (Lima, 2004; Radostits et al., 2007). Nesse período os animais estão expostos a maiores situações de estresse e segundo Carlson et al. (2011) a ocorrência de surtos de coccidiose pode estar relacionada ao desmame, apartamento e mudança de dieta, condições as quais estes bezerros estavam expostos.

De acordo com Lima (2004), a forma mais severa da coccidiose é caracterizada por diarreia profusa, desidratação, anorexia, letargia e alta mortalidade, concordando com os sinais clínicos observados nos animais do presente trabalho, o que poderia evoluir para o óbito, caso o tratamento não fosse realizado precocemente.

O tratamento para coccidiose bovina pode ser realizado por diferentes medicamentos. Entre eles, pode-se citar antimicrobianos, amprólio, decoquinato, antibióticos ionofóros (monensina, salinomicina, lasalocida) e toltrazuril (Mundt et al., 2003; Radostits et al., 2007). Dentre os antimicrobianos as sulfonamidas se destacam por sua grande eficácia no controle da coccidiose de bezerros e cordeiros, particularmente quando aplicados no início da doença, devendo ser utilizada na formulação oral na dose de $140 \mathrm{mg} / \mathrm{kg}$ durante três consecutivos (Lima, 2004; Radostits et al., 2007). No presente trabalho, não foi possível estabelecer quando ocorreu a afecção, mas pode-se comprovar que o sulfametoxazol + trimetoprim na dose de $32 \mathrm{mg} / \mathrm{Kg}$ por via intramuscular, em dose única, foi capaz de sanar os sinais clínicos apresentados pelos animais, observado pela melhora do quadro de diarreia, do pelame e ausência de oocistos no exame de fezes (Figural e Tabela 1). 


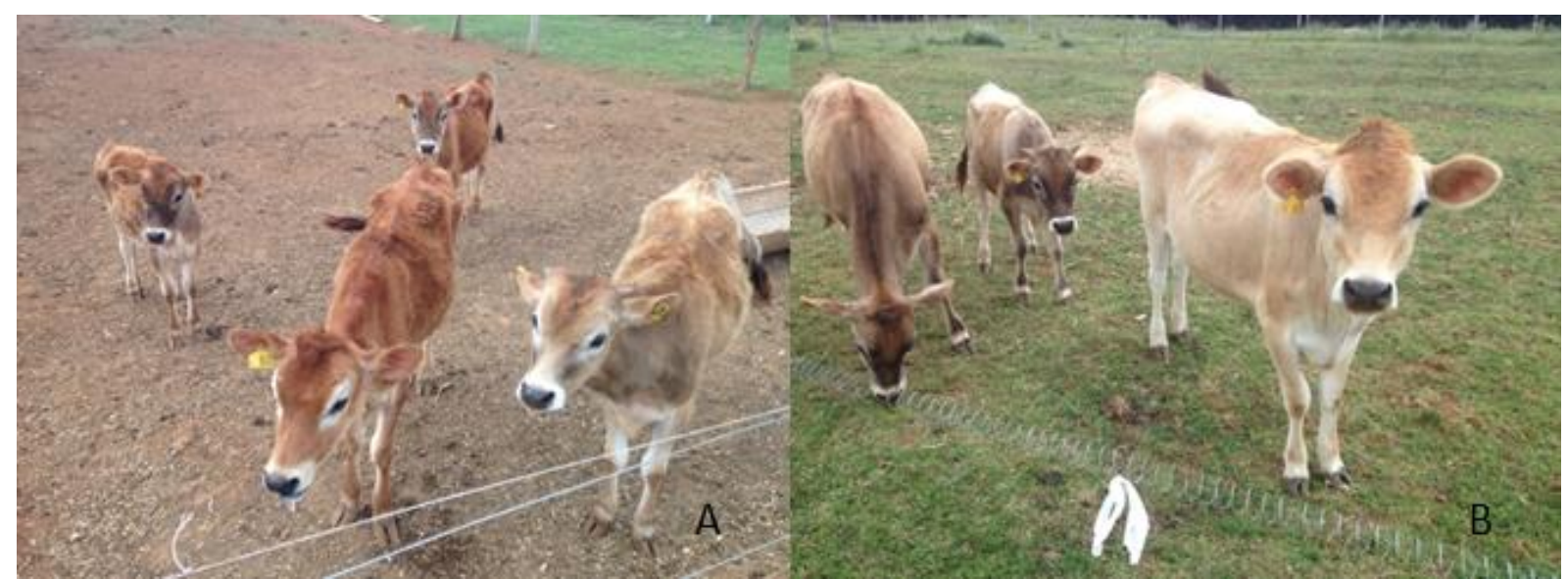

Figura 1. Bezerros com coccidiose antes e depois do tratamento; A- Nota-se animais magros e com pelos opacos e arrepiados antes do tratamento; B- Nota-se melhora do pelame e do escore corporal após o tratamento.

Tabela 1. Valores da presença de oocisto por grama de fezes dos bezerros com coccidiose antes e após o tratamento.

\begin{tabular}{|c|c|c|c|c|c|}
\hline Parâmetro & Grupos & & & nentos & \\
\hline \multirow{10}{*}{$\begin{array}{l}\text { Oocisto de coccidio } \\
\text { (OPG) de fezes }\end{array}$} & \multirow{6}{*}{ Antibiótico + Catofós (C) } & Animal & D15 & D0 & D7 \\
\hline & & 1 & 150 & 150 & 0 \\
\hline & & 2 & 150 & 150 & 0 \\
\hline & & 3 & 250 & 400 & 0 \\
\hline & & 4 & 100 & 250 & 0 \\
\hline & & Média & 162,5 & 237,5 & 0 \\
\hline & \multirow{4}{*}{ Antibiótico (A) } & 1 & 1397 & 150 & 0 \\
\hline & & 2 & 850 & 0 & 0 \\
\hline & & 3 & 100 & 250 & 0 \\
\hline & & Média & 782,33 & 133,33 & 0 \\
\hline
\end{tabular}

D15= 15 dias antes do tratamento, D0= 20 minutos antes do tratamento, D7= sete dias após o tratamento.

$\mathrm{Na}$ Tabela 2 é possível observar os dados referentes ao hematócrito, proteína, fibrinogênio e leucograma dos animais. Notou-se que nenhum destes parâmetros estava fora da normalidade, apesar da presença da doença (Radostits et al, 2007). Tais parâmetros, com exceção do hematócrito, permaneceram estáveis após o tratamento, provavelmente porque a doença foi diagnosticada e tratada precocemente antes que ocorresse a alteração deles.

Em ambos os grupos notou-se aumento do hematócrito, embora os animais não estivessem anêmicos (Radostits et al, 2007), indicando que o próprio controle da doença auxilia na estimulação da eritropoiese, devido à maior oferta de nutrientes para realizar esta função, entretanto no grupo antibiótico mais catofós este aumento foi significativo.O incremento na eritropoiese já foi relatado em cães imunossuprimidos com dexametazona (Deniz et al., 2009).Como a cianocobalamina atua no complexo piruvatodesidrogenase, convertendo o piruvato em acetilcoa, que atuará no complexo enzimático envolvido no ciclo de Krebs e o fósforo é componente de ácidos nucleicos, adenosina trifosfato e adenosina monofosfato (Cunningham, 2002), a oferta exógena destes elementos pode acelerar o processo de eritropoeise, culminando na recuperação mais precoce dos bezerros doentes.

Embora os micro-organismos ruminais produzam quantidades adequadas de cianocobalamina, acredita-se que as lesões intestinais proporcionadas pelos coccídeos afetaram a capacidade de absorção desta vitamina (Moon, 1980; Nielsen, 1982). Desta maneira, o suplemento a base de butafosfan e cianocobalamina só promovem efeito benéficos em ruminantes em situação desafiante, como parto (Rollin et al, 2010; Piccione et al., 2012) ou doenças, como a coccidiose como observado na presente pesquisa.

Os demais parâmetros sanguíneos não sofreram alteração em nenhum dos dois grupos estudados, porém acredita-se que resultados mais expressivos possivelmente seriam encontrados se os animais apresentassem uma forma mais grave da doença. 
Tabela 2. Valores médios dos componentes do eritrograma, leucograma, proteína e fibrinogênio plasmático dos bezerros do grupo antibiótico (A) e antibiótico +Catofós $®(C)$.

\begin{tabular}{|c|c|c|c|c|c|c|}
\hline \multirow[t]{3}{*}{ Paramêtro } & \multirow[t]{3}{*}{ Grupos } & \multicolumn{4}{|c|}{ Momentos } & \multirow[t]{3}{*}{$\mathbf{P}$} \\
\hline & & \multicolumn{2}{|l|}{ D0 } & \multicolumn{2}{|l|}{ D1 } & \\
\hline & & Média & EM & Média & EM & \\
\hline Leucócitos & $\mathrm{C}$ & 11,35 & 1,97 & 11,88 & 1,82 & 0,09 \\
\hline \multirow[t]{2}{*}{$\left(10^{3} / \mathrm{uL}\right)$} & A & 9,43 & 1,76 & 9,73 & 0,66 & 0,8 \\
\hline & $\mathrm{P}$ & 0,51 & & 0,37 & & \\
\hline Neutrófilo & $\mathrm{C}$ & 1,36 & 0,37 & 1,32 & 0,48 & 0,29 \\
\hline \multirow[t]{2}{*}{$\left(10^{3} / \mathrm{uL}\right)$} & A & 1,00 & & 1,11 & & 0,91 \\
\hline & $\mathrm{P}$ & 0,95 & & 0,82 & & \\
\hline Linfócito & $\mathrm{C}$ & 8,81 & 1,47 & 8,12 & 1,72 & 0,16 \\
\hline \multirow[t]{2}{*}{$\left(10^{3} / \mathrm{uL}\right)$} & A & 7,09 & 1,18 & 5,84 & 1,54 & 0,31 \\
\hline & $\mathrm{P}$ & 0,43 & & 0,39 & & \\
\hline Monócito & $\mathrm{C}$ & 1,98 & 0,62 & 1,04 & 0,52 & 0,34 \\
\hline \multirow[t]{2}{*}{$\left(10^{3} / \mathrm{uL}\right)$} & A & 1,68 & 0,26 & 0,64 & 0,05 & 0,07 \\
\hline & $\mathrm{P}$ & 0,71 & & 0,55 & & \\
\hline Eosinófilo & $\mathrm{C}$ & 0,14 & 0,11 & 0,12 & 0,02 & 0,87 \\
\hline \multirow[t]{2}{*}{$\left(10^{3} / \mathrm{uL}\right)$} & A & 0,17 & 0,17 & 0,43 & 0,38 & 0,33 \\
\hline & $\mathrm{P}$ & 0,87 & & 0,37 & & \\
\hline Basófilo & $\mathrm{C}$ & 0,05 & 0,05 & 0,08 & 0,03 & 0,57 \\
\hline \multirow[t]{2}{*}{$\left(10^{3} / \mathrm{uL}\right)$} & A & 0,04 & 0,04 & 0,12 & 0,06 & 0,53 \\
\hline & $\mathrm{P}$ & 0,95 & & 0,51 & & \\
\hline Proteína & $\mathrm{C}$ & 6,13 & 0,13 & 6,1 & 0,17 & 0,31 \\
\hline \multirow[t]{2}{*}{$(\mathrm{g} / \mathrm{dL})$} & A & 6,13 & 0,13 & 6,07 & 0,12 & 0,18 \\
\hline & $\mathrm{P}$ & 0,42 & & 0,89 & & \\
\hline Fibrinogênio & $\mathrm{C}$ & 0,25 & 0,05 & 0,05 & 0,07 & 0,09 \\
\hline \multirow[t]{2}{*}{$(\mathrm{mg} / \mathrm{dL})$} & A & 0,27 & 0,07 & 0,05 & 0,03 & 0,18 \\
\hline & $\mathrm{P}$ & & 0,84 & 0,81 & & \\
\hline HTO & $\mathrm{C}$ & 27,00 & 2,08 & 32,00 & 2,5 & 0,03 \\
\hline \multirow[t]{2}{*}{$\%$} & A & 30,33 & 4,18 & 37,67 & 3,76 & 0,08 \\
\hline & $\mathrm{P}$ & 0,47 & & 0,28 & & \\
\hline
\end{tabular}

$\overline{\mathrm{EM}}=$ Erro padrão da média, $\mathrm{D} 0=20$ minutos antes do tratamento, $\mathrm{D} 1$ = sete dias após o tratamento. $\mathrm{HTO}=$ hematócrito, $\mathrm{C}$ antibiótico + catofos. A- antibiótico.

\section{Considerações Finais}

Neste trabalho foi possível comprovar a eficácia do sulfametoxazol + trimetoprim em aplicação única, na dose de $32 \mathrm{mg} / \mathrm{Kg}$ em dose única no combate da coccidiose. A utilização do bustofan associado a cianocobalamina, em dose única auxiliou no aumento do hematócrito de bovinos com coccidiose.

\section{Referências bibliográficas}

Carlson, J. C., Linz, G. M., Ballweber, L. R., Elmore, S. A., Pettit, S. E. \& Franklin, A. B. 2011. The role of European starlings in the spread of coccidian within concentrated animal feeding opperations. Veterinary Parasitology, 180, 340- 343.
Cunningham, J. G. 2002. Textbook of Veterinary Physiology (3rd ed). W. B. Saunders, Philadelphia, PA.

Deniz, A., Spieckerhauser, U. \& Rehagen, M. 2009. Efficacy of Butafosfan and Vitamin B12 Combination (Catosal B12®) on Biochemical and Hematological Blood Parameters in Dogs Treated with Dexamethasone. International Journal of Apply Research of Veterinary Medicine, 7(3), 116-129.

Lima, J. D. 2004. Coccidiose dos ruminantes domésticos. Revista Brasileira de Parasitologia Veterinária, 13(1), 1.

Moon, H. W. 1980. Intestino. In: Cheville, N. F. Pathologia Celular. Acribia, Zaragoza, ES.

Mundt, H. C., Daugschies, A., Vebe, F. \& Rinke, M. 2003. Efficacy of toltrazuril against 
artificial infection with Eimeria bovis in calves. Parasitology Research, 9 (supp 13), 166-167.

Nielsen, K. 1982. Pathophysiology of gastrointestinal parasitism. In. Mettrick D. F.\& Desser, S. S. Parasites- their World and Ours.: Elsevier, Toronto, Canada.

Oliveira, P. C. L., Sampaio, R. L., Lacerda, M. S., Alvarenga, R. R. \& Espinoza, M. F. 2007. Coccidiose entérica, associada à encefalopatia, em vaca Gir adulta (relato de caso) Ciência Animal Brasileira, 10(1), 322-329.

Piccione, G., Messina, V., Marafioti, S., Casella, S., Giannetto, C., \& Fazio, F. 2012. Changes of some haemato chemical parameters in dairy cows during late gestation, post partum, lactation and dry periods. Veterinaria Medicina e Zootecnia, 58, 59-64.

Radostitis, O. M., Gay, C. C., Hinchcliff, K. W. \& Constable, P. D. 2007. Veterinary medicine: a textbook of the diseases of cattle sheep, pigs, goats and horses (9a ed.). W.B. Saunders, Philadelphia, PA.

Rollin, E., Berghaus, R. D. Rapnicki, P. Godden, S. M. \& Overton, M. W. 2010. The effect of injectable butaphosphan and cyanocobalamin on post partum serum b Hydroxybutyrate, calcium and phosphorus concentrations in dairy cattle. Journal of Dairy Science, 93, 978987.

Recebido: 7 Maio. 2018.

Aprovado: 16 Junho. 2018

Publicado: 10 Setembro. 2018

Licenciamento: Este artigo é publicado na modalidade Acesso Aberto sob a licença Creative Commons Atribuição 4.0 (CC-BY 4.0), a qual permite uso irrestrito, distribuição, reprodução em qualquer meio, desde que o autor e a fonte sejam devidamente creditados. 